\title{
Examining the Relationship between Critical Thinking Skills and Argumentative Writing Skills in Moroccan Preparatory Classes of Higher Engineering Schools (CPGE)
}

\author{
Mounir BENICHE $\mathbf{8}$ (D) $\triangle$, Mohammed LAROUZ ${ }^{2} \mathbf{8}$ (D) and Khadija ANASSE 8 (D) \\ ${ }^{1}$ PhD Researcher, English department Faculty of Languages, letters and Arts, Ibn Tofail University, Kenitra, Morocco; Teacher of \\ English, CPGE (Classes Préparatoires aux Grandes Ecoles), Meknes, Morocco \\ ${ }^{2}$ Full Professor, English department, Moulay Ismail University, Meknes, Morocco; Dean of the Faculty of Arts and Humanities, \\ Moulay Ismail University, Meknes, Morocco \\ ${ }^{3}$ Full Professor, English department, Faculty of Languages, letters and Arts, Ibn Tofail University, Kenitra, Morocco
}

Corresponding Author: Mounir BENICHE, E-mail: Benichemounir@gmail.com

\section{ARTICLE INFORMATION $\quad$ ABSTRACT}

Received: August 18, 2021

Accepted: September 20, 2021

Volume: 4

Issue: 9

DOI: $10.32996 /$ ijllt.2021.4.9.19

\section{KEYWORDS}

Argumentative writing, Critical thinking, Correlation, CPGE students
This research was conducted to investigate the relationship between two variables: critical thinking skills and argumentative writing skills in Moroccan Preparatory Classes of Higher Engineering Schools (Classes Préparatoires aux Grandes Ecoles) ( CPGE), Omar Ibn Khattab Meknes. The participants were the 2nd year Maths and Physics (MP) students in CPGE, Omar Ibn Al Khattab Meknes. 60 students participated in the study from a total number of 120 students. The research adopted the correlation design to measure the degree of association between two variables using the statistical procedure of correlation analysis. In this regard, a critical thinking test (AssessmentDay Practice Test Experts, 2018) was administered to test students' critical thinking skills. Then, the students were asked to write an argumentative essay about social networking and creativity. To analyse the collected data, the study resorted to SPSS software (Statistical Package for the Social Science, version 23). Pearson's correlation coefficient was used to investigate the significant relationship between critical thinking skills and argumentative writing. The result of the research displayed that the correlation coefficient is 0.941 , which means that the two tests are positively correlated and the correlation is very significant. The result of such correlation displayed clearly that critical thinking and argumentative writing have a positive relation.

\section{Introduction}

The goal of tertiary education in the $21^{\text {st }}$ century is not displaying information and knowledge through lecturing but rather creating contexts for interactions, questioning, debating to sharpen students' thinking skills. Technology and social networking offer easy access to a flood of data in different disciplines, and students can get them by themselves. Tertiary education, then, should go beyond data lecturing and offer a learning environment in which the role of the professor is a monitor, facilitator involving students to have a say in the displayed knowledge through inquiries, analysis and synthesis. Self-centred learning involves students in the learning process to be not just consumers of the offered courses but rather active participants in their construction. For Kennedy, Latham and Jacinto (2016), knowledge building in the 21st century is fostered by building a bridge from the known to the new. Yet, unlike traditional knowledge acquisition, students, often in teams, are assisted to become the creators rather than merely the consumers of new knowledge (p.23).

Learning based on communication will offer more opportunities to students to think, reflect and come up with an output that develops both their knowledge and skills. This is the rationale of tertiary education in this new millennial as it has become a platform to enhance thinking skills among students.

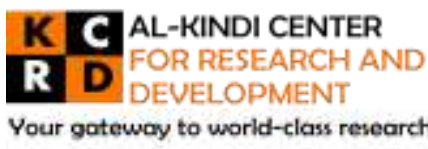

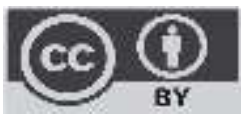

Published by Al-Kindi Center for Research and Development, London, United Kingdom. Copyright (c) the author(s). This open access article is distributed under a Creative Commons Attribution (CC-BY) 4.0 license 
Critical thinking in tertiary education should include six crucial dimensions: (1) core skills in critical argumentation which means reasoning and inference, (2) critical judgments, (3) critical-thinking dispositions and attitudes, (4) critical being and critical actions, (5) societal and ideology critique, and (6) critical creativity or critical openness. This model shows that critical thinking in addition to the individual dimension it refers to the sociocultural one (Barnett \& Davies, 2015, p.8).

Argumentation in tertiary education is the essence of critical thinking as the students question, discuss and express their opinions agreeing and disagreeing about suggested topics using their logic and reason."To question is crucial because it creates the capacity to identify paradoxes, injustices, and contradictions leading to imagining other possibilities"(Barnett \& Davies,2015, p.467). Questioning and arguing push the barriers of taking data for granted and enable students to reach deep learning.

\subsection{Research Problem}

Critical thinking is not a set of skills that should be acquired in a guided context. Rather, it is a way of thinking and is based on reasoning, reflecting, analyzing, synthesizing, evaluating to solve problems and take rational decisions in real life. The developed critical thinking skills in academic context are meant to be transferred to other domains that include the social, the economical, the political, etc., to be more practical and efficient. To reach these goals in tertiary education, critical thinking should be approached in a well-planned coherent reform that invites doers from different fields. It is a cooperation that involves qualified experts in different fields to develop a consistent and a coherent reform.

\subsection{Research Questions and Hypotheses}

To orient the study, a number of research questions and hypotheses have been postulated:

\subsubsection{Research Questions}

1-What is the level of critical thinking skills in Moroccan CPGE ?

2-What is the performance of students in Moroccan CPGE in argumentative writing ?

3-To what extent there is a link between critical thinking skills and argumentative writing in Moroccan CPGE ?

\subsubsection{Research Hypotheses}

1- CPGE students use high order thinking skills

2- CPGE students use argumentative skills in their written performance

3-CPGE students with higher order thinking skills perform well in their argumentative writing

\subsection{Research Objectives}

This study has many objectives: it aims first to examine whether critical thinking skills have an impact on students' argumentative writing. Then, it attempts to examine to what extent Moroccan CPGE students apply critical thinking skills in argumentative writing. It also targets scrutinising the major difficulties Moroccan CPGE students face while dealing with critical thinking skills and suggesting possible solutions. Finally, it tends to draw implications for professors, researchers in the realm of education, syllabus designers and curriculum developers to improve Critical Thinking Skills in Moroccan tertiary education in particular and the Moroccan educational system in general.

\section{Review of Literature}

\subsection{Critical Thinking}

In the world of technology and rapid changes thinking critically has become a must both academically and in everyday life. Questioning, analyzing and synthesizing are highly needed to intellectual dynamism and criticality. Critical thinking is a complex mental process involving paying attention to details, selecting relevant information, analyzing carefully and skeptically, making judgments, and meta-cognitive thinking such as reflection and higher-order planning (Cottrell, 2005). For Lai ( 2011), critical thinking has roots in primary academic disciplines: philosophy, psychology and education. The three separate different academic stands have approached critical thinking from their own vision and concern.

In philosophy, the writings of Socrates, Plato, Aristotle, and more recently, Mattew Lipman and Richard Paul, exemplify the philosophical approach that focuses on the hypothetical critical thinker displaying his/her qualities and characteristics rather than the actions and behaviours he/she can perform (Lai, 2011). The cognitive psychological approach for Lai (2011) is different and in contrast with the philosophical concept in two major points. Firstly, cognitive psychologists tend to study how people actually think versus how they could or should think under ideal conditions (Sternberg, 1986). Secondly, they aim to define critical thinking by the types of actions and behaviors critical thinkers can do, not by the characteristics of the ideal thinker or standards of "good" thought ( Lai, 2011). In education, Benjamin Bloom and his associates are considered the pioneers. Taxonomy for 
information processing skills is an outstanding contribution to teaching and assessing higher order thinking skills. Bloom's taxonomy displays three major highest levels which represents critical thinking skills: analysis, synthesis, and evaluation (Bloom,1956)

\subsubsection{Argumentative Writing}

Developing the ability to argue is imperative in our daily practices. Argumentation is a thinking skill that trains the mind to analyse ideas, make synthesis, solve problems and take decisions. Initiating students to argue and debate in classroom activities is of great importance to learn critical thinking skills and how to respect different views. Students sharpen their skills through an optimal learning environment that paves the way for their innate skills as they are given a chance to express themselves freely.

Classroom debating and arguing can be invested later on to develop students' argumentative writing which is highly required in academic and workplace success. For Dickson (2004), students who debate are invested in the writing for several reasons:

- They feel the responsibility to their fellow debaters, the rest of the class, and other invited audiences, and they feel pressure to perform well in front of their peers.

- They write to be heard and communicate their ideas, not to complete an assignment for the teacher.

- Students know that they will present their papers on a controversial and current subject as part of a team of debaters, and they care about what they write ( p.35).

When involved in a debatable context, students become motivated and highly competitive to perform well in oral and written argumentation. Displaying current social issues and topics related to their own interests will encourage them to participate actively and generate new ideas. Good argumentation is the output of genuine involvement and practice as students learn to argue and debate when put in an academic context that cherishes pluralism and difference.

\subsubsection{The Relation between Critical Thinking and Argumentative Writing}

Critical thinking and argumentative writing are intrinsically related. The criticality of learners is measured in argumentative production as they display the ability to defend their claims through reason. Logical proofs are used as a counter-discourse to refute weak argumentation and logical fallacies that include flawed reasoning. Critical thinking involves reasoning which is a sophisticated learning process eventually communicated orally or in a written form. ( Palmer, 2012) .In argumentative writing, the writer expresses his/her ideas bearing in mind both writing performance and thinking skills. Hence, Well structured argumentation contributes to the development of critical thinking skills.

Introducing students to write without argumentation leads to subjectivity and biased thinking. In classroom activities, reflective reading and writing in highly required as the students have to question, analyse, synthesize and evaluate. Accumulating knowledge in certain contexts without reflection cripples their thinking skills and make them no more than receptive and passive learners. In modern education, students should be trained to think and develop skills in the process of learning.

In the learning of writing, Wade (as cited in Mehta \& Al-Mahrouqi ,2014) suggested the following stages:

1. Asking questions

2. Defining the problem

3. Examining evidence

4. Analyzing assumptions

5. Avoiding emotional/personal reactions

6. Avoiding simplification

7. Considering alternate assumptions

8. Tolerating uncertainty (p. 5) .

Such stages are really critical and enable the writer to have a systematic way of writing based on questioning, examining, analyzing and logical reasoning. In higher education, students are supposed to demonstrate their higher-order thinking skills in a written form as rubrics of assessment make a strong emphasis on students' critical analysis to test their performance. 
EFL argumentative writing is not a matter of putting words, phrases, and sentences in an organizing process but rather a complex process that needs a good understanding of the topic, developing the thesis statement, creating a coherent discourse, and putting ideas into writing. It involves an intellectual capacity for thinking critically (Pei, Zheng, Zhang, \& Liu, 2017, p.32).

\section{Methodology}

The correlational study was adopted to investigate the relationship between students' critical thinking skills and argumentative writing skills in this research. Researchers use the statistical correlation test to describe and measure the degree of association between two or more variables or sets of scores (Creswell ,2012). For McMillian and Schumacher (2006), a correlational design is a non-experimental design that seeks to investigate whether a relationship between variables exists or not through empirical evidence.

\subsection{Participants}

The population of this research was the $2^{\text {nd }}$ year Maths and Physics ( MP) students in CPGE Omar Ibn Al Khattab, Meknes . . 60 students participated in the study from a total number of 120 which means 4 classes. Only 2 classes were selected for the study. Each class included 30 students. The 2 classes represented half of the overall population. 37 males and 23 females and their ages ranged between 18 and 20 years. The study used the purposive sampling technique and was carried out in January 2021

\subsection{Instruments}

The instruments used to conduct this research were a critical thinking test and an argumentative essay. The critical thinking test was used to test students' critical thinking skills and the argumentative essay was used to assess students' performance in argumentative writing.

\subsubsection{Critical Thinking Test}

This study used a critical thinking test to test students' critical thinking skills (Assessment Day Practice Test Experts, 2018). The test follows the paradigm of

Watson Glaser Critical Thinking Appraisal (WCCTA), Form S includes forty items (Watson \& Glaser, 1994; Watson \& Glaser, 2008). It is a multiple-choice test that includes two to five options.

The Watson-Glaser Critical Thinking Appraisal contains five sub-tests that target the theoretical concept of critical thinking and topics for practice.

The five sub-tests include :

1- Inference : discriminating among degrees of the truth of inferences drawn from given data.

2- Recognition of Assumptions: recognizing unstated assumptions or presuppositions in given statements or assertions.

3- Deduction : determining whether certain conclusions necessarily follow from information in given statements or premises.

4- Interpretation : weighing evidence and deciding if generalizations based on the given data are warranted.

5- Evaluation of Arguments : distinguishing between strong and relevant arguments and those that are weak or irrelevant to a particular issue.

To carry out this critical thinking test, the students were allowed 30 minutes.

\subsubsection{Argumentative Writing Skills}

To test students' argumentative writing skills, the students were asked to write an argumentative essay about the following issue: "With the emergence of social networking, people have become less creative". The time allotted for the argumentative writing was 40 minutes.

\subsection{Data Collection Procedure}

The study tried first to explain the tasks they would be carried out by the students. Then, instructions were well clarified, including the structure of the texts, answering questions, and the time allotted for the tasks. The students started by the critical thinking test that is based on multiple-choices options. When they finished and handed in their copies, they would start the second task which was an argumentative essay. In this regard, both tasks were taken in the same session by the same students. 


\subsubsection{Data Analysis Procedure}

For the analysis of the collected data, the study resorted to SPSS software (Statistical Package for the Social Science, version 23). Pearson's correlation coefficient was used to investigate any statistically significant relationship between critical thinking skills and argumentative writing skills.

\section{Results}

\subsection{Critical Thinking Skills}

The Histogram displays the result of the critical thinking test which was taken by 60 participants in Moroccan CPGE Omar Ibn Al Khattab, Meknes. There were 40 multiple-choice questions and the correct answers are as the following:

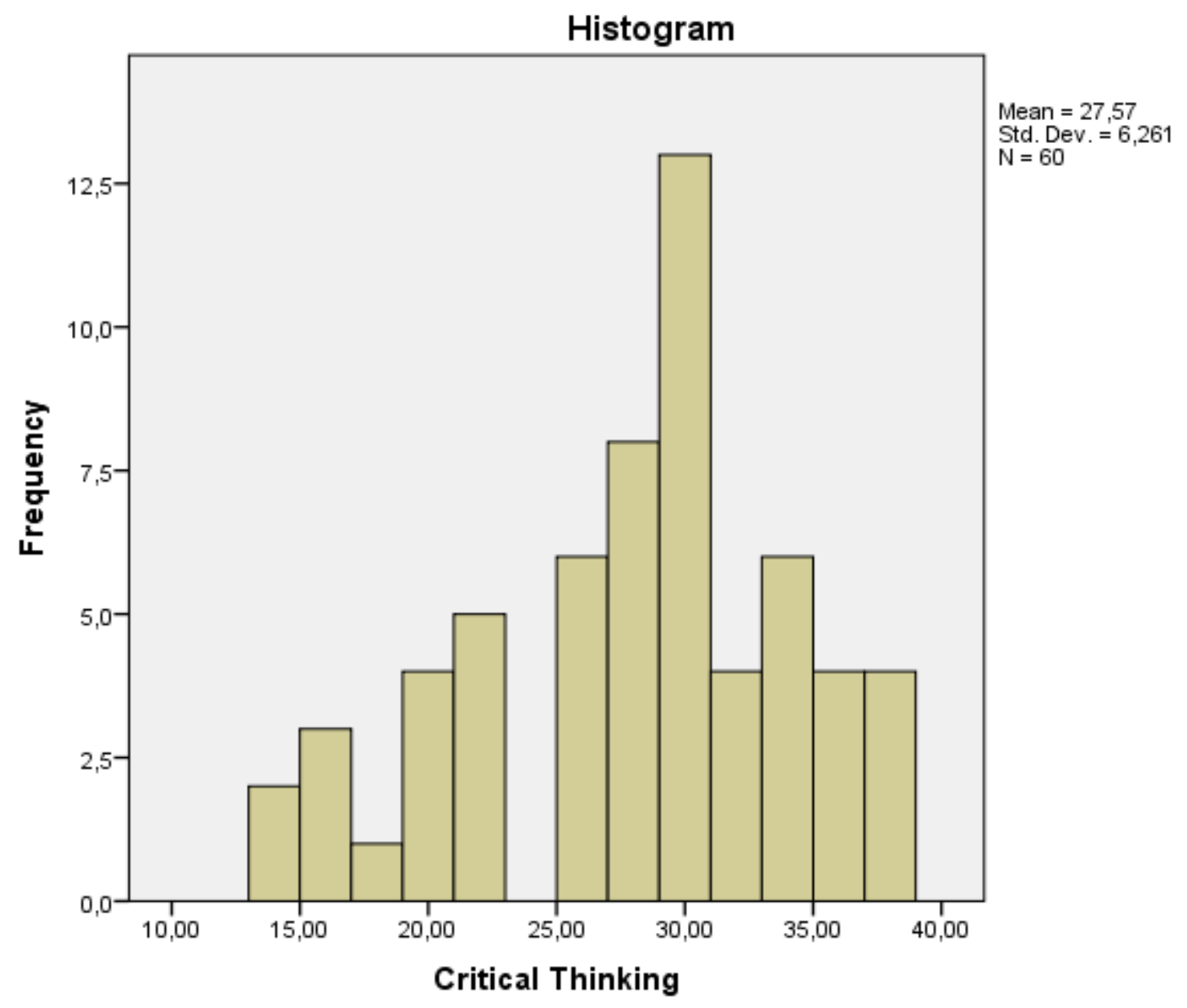

Figure 1 Critical Thinking

The revealed results can be divided into three major categories. For example, in category $1: 6$ students were below the average. In category $2: 36$ students who scored between 20 and 30. In category $3: 18$ students who scored between 31 and 38 . Hence, in the first category only 6 students had difficulties in critical thinking while the majority, which was 36 was quite good and the last category of 18 were very good students. The displayed results confirm the alternative hypothesis and reject the null hypothesis. CPGE students use high order thinking and can infer, deduce, recognize assumptions, interpret and evaluate arguments.

\subsection{Argumentative Writing Skills}

The achievement of Moroccan CPGE students in argumentative essay is illustrated in the following diagram: 


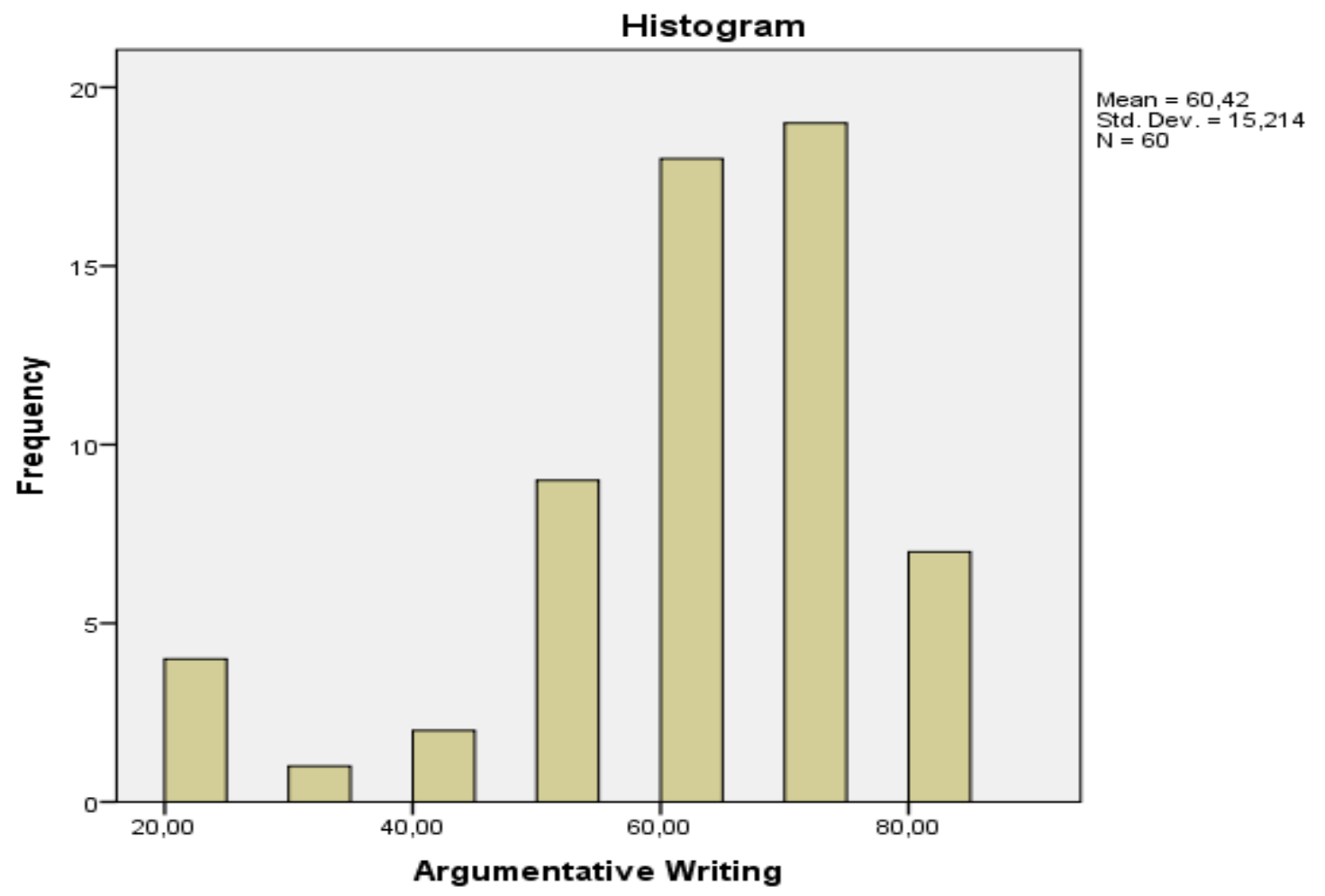

Figure 2. Argumentative Essay Performance

60 participants were asked to develop an argumentative essay about the following statement: "With the emergence of social networking people have become less creative". Arguing for or against with respect to the form and the content of the argumentative writing. The produced argumentative essays were corrected by Two raters who are teachers in preparatory classes of higher engineering schools and the scoring criteria included: Introduction ( General background and thesis), Main points (Body Paragraphs, Refutation and Conclusion), Organization, Mechanics and Sources (Schwalm ,2007)

7 participants scored below the average in the argumentative essay performance, 41 scored between 50 and 70 , and 12 participants were between 70.50 and 80.50 . The results revealed that the majority of participants (41) are quite good, only 7 participants are below the average, while 12 participants are very good in argumentative writing. Hence, the alternative is accepted and the null hypothesis is rejected. The obtained results assert that CPGE performs well in an argumentative essay as they use logical argumentation to support their views with respect to the structure of writing.

\subsection{Interrater Reliability}

Inter-rater reliability (IRR) is a measure used to examine the degree of agreement between two coders or more about independent coding choices to determine coding consistency. Cohen's kappa is considered one of the most reliable measures of IRR and is used widely in academic research studies. The scores of kappa can range from -1 to 1 . -1 presents perfect disagreement, 0 indicates no noticeable pattern in code agreement, and 1 shows perfect agreement (Elsner, 2014, p1).

In this study, to measure the agreement between the two raters, Cohen's Kappa coefficient was implemented and the result was the following:

Symmetric Measures

\begin{tabular}{|l|l|l|l|l|}
\hline & Value & $\begin{array}{l}\text { Asymptotic } \\
\text { Standardized } \\
\text { Error }\end{array}$ & Approximate T & $\begin{array}{l}\text { Approximate } \\
\text { Significance }\end{array}$ \\
\hline $\begin{array}{l}\text { Measure of Agreement Kappa } \\
\text { N of Valid Cases }\end{array}$ & 60 &, 540 & 11,373 &, 000 \\
\hline
\end{tabular}


The table of symmetric measures displayed the value of the Cohen's Kappa index which is a statistic designed to account for agreement by chance between the two raters. The Cohen's kappa $(K)$ is $\mathbf{0 . 5 4 0}$ which is the proportion of agreement happening by chance. Cohen's kappa ( $\mathrm{k}$ ) can range between -1 to +1 . A Cohen's Kappa index of 0.540 represents moderate agreement . Hence, since $p=.000$ (which actually means $p<.0005$ ), the current kappa coefficient $(\mathrm{k})$ is statistically significantly different from zero. Inter rater reliability is crucial as it is representing the extent to which the gathered data in a certain research study are genuine representations of the measured variables.

\subsection{Critical Thinking and Argumentative Writing}

The critical thinking test taken by CPGE students displayed the minimum score was 14 , the maximum score was 38 , the mean was 27.5667, and the standard deviation was 6.26090. For the second task, the argumentative essay, the minimum score was 20 , the maximum score was 80.50 , the mean was 60.4167 , and the standard deviation was 15.21433 .

\section{Table 1 : Critical Thinking Test and Argumentative Writing}

\begin{tabular}{|l|l|l|l|l|l|}
\hline & N & Minimum & Maximum & Mean & Std. Deviation \\
\hline Critical Thinking & 60 & 14,00 & 38,00 & 27,5667 & 6,26090 \\
Argumentative Essay & 60 & 20,00 & 80,50 & 60,4167 & 15,21433 \\
Valid N (listwise) & 60 & & & & \\
\hline
\end{tabular}

\subsection{Correlation between Critical Thinking and Argumentative Writing}

Pearson's correlation was used to investigate the relationship between critical thinking and argumentative writing.

Table2: Correlation between Critical Thinking and Argumentative Writing

\section{Correlations}

\begin{tabular}{|ll|l|l|}
\hline & & Critical Thinking & $\begin{array}{l}\text { Argumentative } \\
\text { Essay }\end{array}$ \\
\hline Critical Thinking & Pearson Correlation & 1 &, $941^{\star \star}$ \\
& Sig. (2-tailed) &, 000 \\
& $\mathrm{~N}$ & 60 & 60 \\
\hline Argumentative Essay & Pearson Correlation &, $941^{* *}$ & 1 \\
& Sig. (2-tailed) &, 000 & 60 \\
& $\mathrm{~N}$ & 60 & \\
\hline
\end{tabular}

**. Correlation is significant at the 0.01 level (2-tailed).

The correlation coefficient is $\mathbf{0 . 9 4 1}$ which means that the two tests are positively correlated and the correlation is very significant. The result of such correlation displayed clearly that critical thinking and argumentative writing have a positive relation. Students who scored high on the critical thinking test are better at their argumentative writing. In this regard, the null hypothesis which states that there is no relation between critical thinking and argumentative writing, was rejected and the alternative hypothesis was accepted.

\section{Discussion}

The findings of this research expressed a strong correlation between critical thinking and argumentative writing in Moroccan CPGE, Omar Ibn Al khatab, Meknes. Similar results were revealed in other studies : (Putri , 2018) ; (Sugianto ,2014) and (Saputra ,2018). However, other studies could not find significant correlation between critical thinking skills and argumentative writing and ended up with different results. For instance, (Pei, Zheng, Zhang \& Liu, 2017) and (Fahim \& Nilforooshan, 2014). 
The results of this study display clearly the importance of critical thinking skills in tertiary education. Students with higher-order thinking skills are independent learners and thinkers who can use their mental capacities to make a difference and create new output in many fields. They are not passive learners who consume certain data in guided contexts, but rather active learners who analyze, synthesize, evaluate, solve problems and take decisions in varied contexts. Training students to think critically empowers them in an academic context, at work and in everyday life. They can perform well in language proficiency, including reading, speaking, listening, and writing ; they transform the acquired knowledge and skills to their workplace and daily practices.

\section{Conclusion}

This research study aimed to examine the relationship between critical thinking and argumentative writing among Moroccan CPGE students. The study results revealed that the critical thinking of CPGE students was high and they used high order thinking through the displayed critical thinking test that includes: inference, recognition of assumption, deduction, interpretation and evaluation of arguments. Students with high order thinking skills perform well in their argumentative writing. In addition to that, students' performance in argumentative writing was good as they mastered the techniques of argumentation and the use of logical reasoning to defend their point of view about the suggested topic.The research study concluded by the result that there was a significant positive relationship between critical thinking and argumentative writing among Moroccan CPGE students.

\section{Recommendations and Implications}

Many recommendations and implications should be drawn from the results of this study:

a) Critical thinking skills should be given much focus in tertiary education and the whole educational system.

b) Students in tertiary education are future leaders who should be given voice in classroom environment to sharpen their thinking skills and dispositions.

c) In 21st century education, there is no room for rote learning based on memorization and the cramming of information.

d) Creating an optimal learning environment should be a priority to help professors do their work properly and make students motivated and more productive.

\section{References}

[1] AssessmentDay Practice Test Experts (2018). Sample critical thinking tests. Retrieved from https://www.assessmentday.com/watson-glasercritical-thinking.htm

[2] Barnett, R., \& Davies, M. (2015). The Palgrave handbook of critical thinking in higher education. New York: Palgrave Macmillan

[3] Bloom, B.S., Engelhart, M. D., Furst, E. J., Hill, W. H., \& Krathwohl, D.R. (1956). Taxonomy of educational objectives: The classification of educational goals; Handbook I: Cognitive Domain. New York: Longmans.

[4] Cottrell, S. (2005). Critical thinking skills: Developing effective analysis and argument. Palgrave Macmillan

[5] Creswell, J.W. (2012). Educational research: Planning, conducting, and evaluating quantitative and qualitative research .(4 ${ }^{\text {th }}$ ed.) . Boston: Pearson Education.

[6] Dickson, R. ( 2004). Developing "real-world intelligence": Teaching argumentative writing through debate. The English Journal: Re-Forming Writing Instruction, 94 (1), 34-40.

[7] Fahim, M., \& Nilforooshan, S.(2014). The relationship between critical thinking and foreign language anxiety.International Journal of Language Learning and Applied Linguistics World,5 (3),136-148.

[8] Kennedy,I.G., Latham,G., \& Jacinto, H. ( 2016). Education skills for 21st century teachers : Voices from a global online educators' forum. Springer

[9] Lai, E. R. (2011). Critical thinking: A literature review research report. Parsons Publishing.

[10] Mehta, S. M., \& Al-Mahrouqi, R. (2014). Can thinking be taught? linking critical thinking and writing in an EFL context. RELC Journal, 46 (1), $1-14$.

[11] Pei, Z., Zheng, C., Zhang, M., \& Liu, F. ( 2017).Critical thinking and argumentative writing: Inspecting the association among EFL learners in China. English Language Teaching, 10 (10), 31-42.

[12] Palmer, W. (2012). Discovering arguments: An introduction to critical thinking, writing, and style.(4 ${ }^{\text {th }}$ ed). Pearson Prentice Halll.

[13] Putri,R.O. (2018). Investigating the link between critical thinking skill and argumentative writing skill: The case of Islamic senior high school. Edukasi:JurnalPendidikanDan Pengajaran,5(2), 144-153.

[14] Saputra, A.J. (2018).The correlation between critical and writing achievement of the fifth semester students of English education study program of Uin Raden Fatah Palembang. Retrieved from https://zenodo.org/record/1293289\#.YQp4Ffk6_IU

[15] Schwalm, K. (2007). Rubric for the Assessment of the Argumentative Essay. Retrievedfromhttps://web.gccaz.edu/english/assessment/spring07/final/ArgumentRubric.htm

[16] Sugianto, A. (2014).The Relation between critical thinking ability and writing ability:(A Correlational study of the sixth semester students of department of english.education of Syarif Hidayatullah State Islamic University Jakarta). BA. Thesis, State Islamic University.

[17] Wade, C. (1995). Using writing to develop and assess critical thinking. Teaching of Psychology, 22 (1), 24-28.

[18] Watson, G. B., \& Glaser, E. M. (1994). Watson-Glaser critical thinking appraisal Form S manual. San Antonio, Harcourt Brace.

[19] Watson, G., \& Glaser, E. M. (2008). Watson-Glaser Critical Thinking Appraisal Short Form Manual. Upper Saddle River, Pearson Education. 